Copyright (C) 2021 by Cherkas Global University

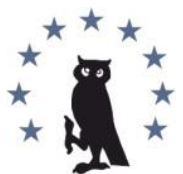

Published in the USA

Slavery: Theory and Practice

Has been issued since 2016.

E-ISSN: 2500-3755

2021. 6(1): 58-65

DOI: $10.13187 /$ slave.2021.1.58

https://stp.cherkasgu.press

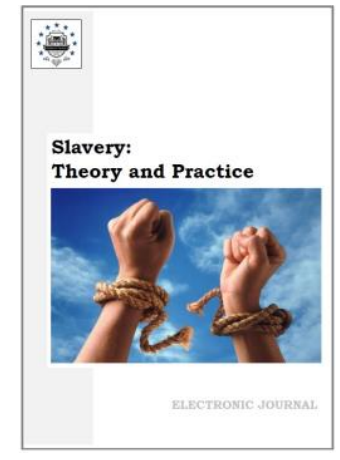

\title{
Reviews
}

\section{The Circassian Slave Narratives (A Documentary Collection). Compiler and author of the introductory article A.A. Cherkasov. Bylye Gody. 2020. Vol. 57-1. Is. 3-1: 1415-2266 (A Special Issue)}

\author{
Vladimir P. Trut a * \\ ${ }^{a}$ Don state technical University, Rostov-on-don, Russian Federation
}

\begin{abstract}
The review analyzes the collection of documents "Circassian slave narratives". Special attention is paid to the consideration of the scientific article of the author-compiler of the collection A.A. Cherkasov, which precedes its main content. The content of this collection of documents is comprehensively characterized, the important, interesting, diverse source materials presented in it are analyzed, the vast majority of which are introduced into scientific circulation for the first time. The origin and main content of the documents included in the collection are characterized, the most important and interesting of them are considered. The scientific relevance and significance of the documents presented in the collection for further research on the problems of Russian-Circassian relations during the Caucasian War, the socio-economic development of Circassian society is determined.

Keywords: Circassian slave narratives, collection of documents, Circassia.

В конце 2020 года в специальном выпуске авторитетного научного исторического журнала «Былые годы», входящего в ведущие международные наукометрические базы данных, был опубликован фундаментальный сборник документов «Черкесские невольничьи повествования» (Сборник документов) ${ }^{1}$. Представленные в нём документальные материалы посвящены актуальной научной проблеме существования в черкесском обществе таких специфических социальных и экономических явлений, как рабовладение и крепостничество. При этом данные явления освещаются сквозь призму как официальной документации самого разного характера русских военных и гражданских властей рассматриваемого периода, так и такого важного, интересного, хотя, естественно, и своеобразного первоисточника, как свидетельства бывших черкесских пленников-рабов и местных жителей, находившихся на положении как рабов, так и зависимого крепостного населения.

Автором-составителем данного сборника документов и автором вводной научной статьи, содержащей комплексный научный анализ, основанный на использовании целого

\footnotetext{
${ }^{*}$ Corresponding author

E-mail addresses: trut.vladimir@rambler.ru (V.P. Trut)

${ }^{1}$ Черкесские невольничьи повествования (Сборник документов). Автор-составитель и автор вводной аннотированной статьи А.А. Черкасов. Cherkasov A.A. (2020). The Circassian Slave Narratives (A Documentary Collection). Bylye Gody. 57-1(3-1): 1415-2266.
} 
ряда общенаучных и специальных научных исторических исследовательских методов, включая специальные источниковедческие, является доктор исторических наук, научный сотрудник Международного сетевого центра фундаментальных и прикладных исследований, член Восточно-Европейского исторического общества Александр Арвелодович Черкасов.

Масштабная и кропотливая работа по выявлению, систематизации и анализу разноплановых документов и материалов, вошедших в названный сборник, осуществлялась автором на протяжении длительного времени в Государственном архиве Краснодарского края. Именно в данном архивном хранилище сосредоточен поистине колоссальный и, к сожалению, вплоть до настоящего времени всесторонне и обстоятельно не исследованный корпус документального материала различного происхождения и характера, отражающего существовавшие в черкесском обществе и очень сильно влиявшие практически на все стороны его жизнедеятельности и развития рабовладельческие и крепостнические отношения.

Содержащиеся в сборнике документы были выявлены в 15 фондах Государственного архива Краснодарского края. Подавляющее большинство из них впервые вводится в научный оборот.

В структурно-содержательном плане рецензируемый сборник включает в себя вводную аннотированную статью (С. 1415-1434)', список используемых в сборнике сокращений слов и выражений (С. 1434), основную часть, содержащую подборку архивных документов, представленных в строгом хронологическом порядке (С. 1435-1907), приложение (С. 19082177), общий перечень размещённых в сборнике документов (С.2178-2206), список номеров и названий фондов Государственного архива Краснодарского края использованных при подготовке сборника (С. 2207), именной (С. 2208-2253) и географический указатели (C. 2254-2265), а также содержание сборника на английском и русском языках (С. 2266).

B предваряющей рассматриваемый сборник документов аннотированной статье, являющейся, по сути, предисловием к нему в виде компактного научного исследования представленного корпуса источников, автор проанализировал их общий количественный и содержательный состав, характер происхождения и общее содержание.

Он отметил, что данное им сборнику документов общее и в определённой степени условное название «Черкесские невольничьи повествования» в некоторой мере перекликается с произведениями, написанными в XVIII-XIX веках в известном жанре «невольничьих повествований». Эти произведения, как правило, отражали жизнь рабоввыходцев из Африки и их потомков на территории Северной Америки и представляли собой рассказы, записанные со слов невольников. Они имели не только большую популярность у читателей, но и представляли собой довольно ценный, хотя и своеобразный исторический источник. Однако воспоминаний бывших черкесских пленников и рабов ни в то время, ни позже никто не собирал и, естественно, нигде не публиковал. И поскольку вплоть до настоящего времени аналогичных изданий, отражающих основное содержание и особенности жизнедеятельности находившегося на территории Черкессии населения, относящегося к категории рабского, в отечественной исторической литературе не представлено, предлагаемое издание должно заполнить имеющуюся историческую лакуну.

Осуществив выявление, систематизацию и внешнюю критику источников, автор правомерно констатировал, что выявленные документы не представляют сплошного массива, охватывающего все годы указанного хронологического периода. В представленной им первой диаграмме отчётливо видно, что появление делопроизводственных и иных документов в течение различного времени и, соответственно, их количественное распределение по отдельным годам неравномерно. В течение некоторых лет, например в 1810, 1813 и 1823 годах, их количество было гораздо больше среднего по сравнению с предыдущими и последующими периодами, а в отдельные годы, в частности в 1825, 1826, 1849, 1856 годах, таковые вообще отсутствовали. Данный факт, по мнению автора, объясняется объективными обстоятельствами плохой читаемости документов, особенностями их архивной систематизации хранения и, соответственно, возможностями

\footnotetext{
1 Присутствующая в рецензируемом сборнике документов, изданного в журнальном формате, нумерация страниц обусловлена правилами, существующими в печатных периодических изданиях данного плана. Она является сквозной, начинается с первого номера журнала конкретного года и завершается в последнем номере журнала данного года. - В.Т.
} 
работы с ними исследователей. Основываясь на статистических материалах по демографии Черкесии первой половины XIX в. А.А. Черкасов рассмотрел демографическую ситуацию в крае и, что важно, социальный состав местного разноплеменного горского населения. Он заключил, что зависимость в черкесском обществе была достаточно значительной, особенно в Причерноморье, где находились центры кавказской работорговли, и что даже после махаджирства около трети местного черкесского населения относилось к зависимым крестьянам и рабам (С. 1418-1419). Стремясь осветить обозначенную проблему максимально обстоятельно и всесторонне, автор охарактеризовал её отражение в сочинениях различных путешественников и эмиссаров (С. 1419-1421). При этом можно полностью согласиться с авторским заключением о том, что отражение так называемого обычного черкесского права в источниках личного происхождения путешественников и эмиссаров является слабо достоверным свидетельством о правах рабов и крепостных на территории Черкесии (С. 1430).

В отдельном параграфе раскрываются вопросы генезиса, сущности и развития рабства в Черкесии, участия в захватах пленников и их обращения или продажи в рабство не только черкесов, но и абхазцев и представителей других горских народов данного региона. Автор, основываясь на анализе значительного массива разнопланового источникового материала и историографических наработок различных периодов, совершенно правомерно констатировал, что, «помимо набегов на Кавказе, и в частности на территории Черкесии, были распространены внутренние войны между черкесскими соседними племенами или аулами, а также похищение людей внутри собственных горских обществ» (С. 1421). Всё это предпринималось с целью захвата любых пленников и доставки их в качестве своеобразного живого товара на невольничьи рынки в самой Черкесии, которые действовали в устьях всех крупных рек на её причерноморском берегу (Там же). Данное заключение подтверждается и ссылками на документы, представленные в рассматриваемом сборнике (Там же). В развитие данного аспекта следует отметить, что непосредственно в представленном сборнике документов присутствуют очень интересные и весьма красноречивые в данном плане документальные источники, например документы 1171, 1173, 1174, отражающие даже факты добровольной продажи черкесами своих жён (С. 1894-1895).

Необходимо отметить и ещё одно существенное авторское заключение, также основанное на анализе выявленных архивных документов и не получившее, к сожалению, необходимого освещения в историографии, о том, что в 1805 г. черкесы практически утратили интерес к взаимному обмену пленных. Русские власти сразу обратили внимание на это обстоятельство и оперативно на него отреагировали. В результате уже в апреле 1806 г. последовало личное распоряжение императора о необходимости выкупа русских пленников (C. 1422).

Несомненный интерес представляет и составленная автором таблица, в которой отражено распределение перешедших на русскую сторону выходцев из Черкессии в различные годы обозначенного хронологического периода и, что особенно важно, назван их социальный статус (С. 1425-1426, таблица 4). Из общей численности «перебежавших» горцев в 2878 человек 156 человек являлись дворянами (С. 1426). При этом и сам факт перехода к русским горцев, являвшихся представителями высшего сословия, и их численность заслуживают, по нашему мнению, внимания и дальнейшего анализа.

Автор установил, что двумя основными группами, вышедшими из Черкесии в период 1792-1861 годов, были горцы, как непосредственно черкесы, так и представители других горских народов, всего 1089 человек, или 38 \% от общей численности, и русские, численность которых составила в целом 36 \% от общего числа перебравшихся на русскую территорию. Остальное количество составляли ногайцы, армяне и представители других народов (С. 1428).

По мнению А.А. Черкасова, общее количество ушедших из Черкесии людей, по неполным данным, составляет не менее 6 тыс. человек. При этом побудительные причины их бегства из Черкесии на территорию, контролируемую русскими властями, были достаточно разнообразны. Среди прибывших большинство являлось черкесами, а вторую по численности группу составляли бежавшие из неволи русские военные, казаки, представители мирного гражданского населения, женщины и дети, большинство из которых были захвачены в ходе набегов черкесов на казачьи станицы. Всего же, по данным автора, который правомерно отмечает их неполноту, через черкесское рабство прошли 
представители порядка 20 народов и народностей, среди которых были черкесы, русские, абазины, татары, турки, греки, кабардинцы, калмыки, грузины, армяне, молдаване, австровенгры, поляки, немцы, болгары, евреи, литовцы, ряд малочисленных народов, проживавших в различных географических, иногда весьма значительно удалённых от Кавказа, регионах, и даже уроженцы Африканского континента. Их жизнь в неволе была поистине ужасна. Можно полностью согласиться с итоговым авторским заключением, основанном на объективном и всестороннем изучении очень широкого и разнопланового источникового материала, о том, что «положение рабов и крепостных в черкесском обществе было практически бесправным. И первые, и вторые в любой момент могли быть проданы своим хозяином, в том числе по отдельности. Зависимым нередко наносились увечья, в том числе влекущие в последующем смерть. Балансируя между жизнью и смертью, рабы в Черкесии постоянно находились в депрессивном состоянии. Многие из них подвергались религиозному и этническому преследованию. Часть пленников, не имея возможности избавиться от рабства, кончала жизнь самоубийством» (С. 1430).

Основную часть рецензируемого сборника документов составляют, естественно, представленные в нём архивные документальные источники. В сборнике содержится 1200 разных по своему характеру документов, относящихся к периоду 1792-1861 годов. Доминирующий источниковый массив составляет различная официальная делопроизводственная документация представителей русской военной администрации, рапорты, представляющие большинство документов данного плана, различные донесения, отношения (докладные), отчёты, ведомости о состоянии карантинов при воинских заставах и выписки из журналов о состоянии тех или иных карантинных контор, именные списки и материалы опросов бежавших и выкупленных из плена, ведомости (пофамильные списки) горцев, «вышедших из Закубани или с гор».

Основываясь на фундаментальных исследовательских принципах историзма, объективности и научности, автор-составитель сборника выявил и включил в него практически все доступные в настоящее время документы, в той или иной мере затрагивающие рассматриваемую проблему. При этом он, естественно, прежде всего исходил из их научной новизны, ценности и принципиально дистанцировался от какихлибо политико-идеологических и иных сугубо субъективных критериев. В качестве примера, причем весьма показательного, можно привести представленные в сборнике документы, свидетельствовавшие о таком негативном для русской армии явлении, как дезертирство и бегство солдат к горцам. Например, документ 225 «Рапорт военному губернатору Розенбергу от войсковой канцелярии. 23 марта 1804 г.», в котором, в частности, говорится об обмене егеря 12-го егерского полка Алексея Смольянинова, «учинившего побег за Кубань истекшего года в ноябре месяце» (С. 1534-1535); документ 226 «Ведомость о состоянии карантина при Екатеринодарской заставе. Март 1804 г.», содержащий, среди прочего, сведения о выходе и обмене солдата и казака, самовольно бежавших ранее к горцам (С. 1535).

Или, например, содержание документа номер 1135 «Правила о поступлении с пленными и добровольными выходцами из горцев. 6 июля 1847 г.», подписанные лично главнокомандующим Отдельным Кавказским корпусом генерал-адъютантом князем Воронцовым 6-го июля 1847 года, в котором говорится о том, что «1) военно-пленными считаются: а) Горцы всякого возраста и пола (!!!-В.Т.), взятые в плен нашими войсками; 2) Военно-пленные, без различия пола и возраста (!!!-В.Т.), остаются в продолжении трех месяцев в ближайших крепостях или укреплениях, для размена русских пленных в горах находящихся; 3) взятых целыми семействами в плен разменивать не иначе как семействами же, допускается исключение в таком только случае, если родители сами пожелают отдать кого-либо из детей горцам на обмен наших пленных» (С. 1871). То есть, как видим, русские войска во время ответных набеговых действий могли брать в плен не только горцев, но даже и членов их семей с целью дальнейшего обмена на захваченных черкесами русских мирных жителей. Суровые реалии войны порождали и жёсткие и зачастую жестокие её правила. При этом, правда, следует отметить, что обращение к пленным горцам, особенно к мирному горскому населению со стороны русских властей было более чем гуманным. В данных правилах подчёркивалось, что в случае, если пленённые горские девушки по каким-либо причинам не будут обменяны, то они могут оставаться жить в приютивших их русских семьях, строго указывалось на недопустимость по отношению к ним каких-либо негативных 
действий, о том, что они «ни в каком случае не могут быть причислены к крепостному состоянию» (С. 1872). Более того, рядовым военнослужащим и гражданским лицам разрешалось «по обоюдному согласию» вступать с ними в законный брак, «если они для замужества с христианами примут Св. крещение, достигши установленного возраста и изъявив согласие на таковой союз» (С. 1872). При этом предписывалось: «Местное военное начальство строго обязано наблюдать, чтобы пленницы не иначе были обращаемы в христианскую веру, как по собственному их убеждению, по добровольному желанию и не прежде как по изучении догматов православной церкви; причем вменяются в ответственность, чтобы отнюдь не было употребляемо насильственных или обольстительных мер» (С. 1872). А «каждому нижнему чину, женившемуся на пленнице, предоставляется испрашивать для первоначального обзаведения по 45 руб. серебром» (С. 1872).

В сборнике документов присутствуют также и некоторые довольно интересные и весьма специфические источниковые материалы, отражающие особые сферы взаимоотношений русских властей и горцев, например документ номер 258 сборника «Клятвенное обещание и присяга черкесов русскому царю», датированный маем 1805 года (С. 1549-1550). Это присяга русскому императору трёх влиятельных представителей черкесской знати, в тексте не указано князей или дворян-уорков, знатность которых подчёркивала приставка «бей» в их фамилиях, и 120 человек их подданных, социальный статус которых в документе также не отмечен и определён общей фразой «их люди».

Представлены и достаточно редкие документальные материалы, отражающие способы взаимоотношения русских властей и горцев в плане обмена и выкупа пленников из черкесского рабства: документ номер 813 сборника «Расписка черкесского дворянина К. Немирова о получении денег за пленных» от 4 апреля 1830 года (С. 1750); выделения финансовых средств на содержание вышедших с гор на русскую территорию горцев, например, документ 1064 сборника «Ведомость о средствах выданных для продовольственного обеспечения черкесов в татарском селении Ады» за январь 1842 года (С. 1840-1842).

Другую группу представленных в сборнике документов составляют 180 различных материалов опросов бежавших или выкупленных из черкесского плена русских солдат, казаков и членов их семей, представителей других сословий, а также захваченных горцами граждан других государств и «вышедших» с гор на русскую территорию горцев разных национальностей, включая и черкесов-рабов и крепостных. При этом, и данное обстоятельство является весьма примечательным, именно опросы последних представлены наиболее широко.

Значительное внимание исследователей, помимо собственно представленных в рассматриваемом сборнике документов, несомненно, заслужит и сформированное автором в результате значительной поисковой исследовательской работы «Приложение» в виде «Таблицы 5», озаглавленной «Лица, вышедшие из Черкесии в 1792-1861 годах». В данном приложении содержатся данные о фамилиях и именах, национальности (как написано в оригинальном тексте «племени»), принадлежности к конкретному сословию, возрасте, пояснениях, откуда бежал и куда пришёл («вышел») бывший черкесский пленник, причине бегства, а также номера фондов, описей, дел и листов ГАКК, откуда была извлечена представленная в данной таблице информация. Весьма показательно, что в данной таблице содержатся сведения о 2787 бывших черкесских инонациональных пленниках и собственно черкесах и членах их семей, являвшихся рабами своих соплеменников или находившихся в крепостной зависимости и подвергавшихся различным формам дискриминации и угрозам продажи или даже их жизни (С. 1908-2177). Эти данные отчётливо являются персонифицированными конкретными свидетельствами лиц, непосредственно испытавших на себе рабское и иное зависимое положение, обусловленные им физические и душевные муки и тяготы. Они зримо свидетельствуют не о каком-то абстрактном, общем и размытом черкесском рабстве, а о сущности и размерах черкесского рабства как непосредственного конкретного исторического явления, отличавшегося своими большими масштабами и существовавшего на протяжении очень длительного времени. По сути дела, многие содержащиеся в данном приложении сведения, основанные на расспросах и показаниях непосредственно самих бывших черкесских узников, являются уникальным 
первоисточником, личными свидетельствами бежавших или выкупленных у горцев рабов, то есть настоящими «невольничьими повествованиями».

Несмотря на то, что все содержащиеся в данном приложении-таблице сведения представляют очевидный исследовательский интерес, особо следует отметить содержание графы «причина бегства» (имеется в виду из плена). В ней, в частности, встречаются и просто отдельные слова или группа слов, например, «пленён», «схвачен», «схвачен черкесами», «бежал», «выбежал», «выбежал из плена»; и весьма характерные слова просто «продан», относящиеся не только к пленникам разных национальностей, сословий и рода занятий, но и к бывшим зависимым членам собственно черкесского общества; и более развёрнутые характеристики обстоятельств дела, например «схвачен черкесами, продан, бежал». Присутствуют и крайне любопытные, иногда просто неординарные фразы, сами по себе могущие стать предметом специального рассмотрения, например, «бежал с казаком и 13 греками», «планировал перейти на сторону русских с семьей и несколькими семействами соседей. Хозяин, узнав об этом, отправил его в цепях в горы на жительство. Оттуда он и бежал, сломав железные цепи» (в данном случае речь шла о кабардинце Умогоже Усишове, C. 1915), «Взятый в плен в Польше татарами. Бежал из плена»» (речь шла о русском Семене Коньме, пленённом в 1795 году (С. 1916), ногаец Абдула «говорит на русском языке. Желает принять православную веру. В плену 12 лет. Бежал с женой» (С. 1917).

Достаточно часто встречаются фразы «вышел вместе с семьёй», то есть перешедший на русскую сторону бывший житель черкесской территории, а иногда даже указываются анонимные ногайские женщины, с прочерком в графе «фамилия имя», с указанием «выбежала с семьей» и даже «выбежала с детьми и подвластными» (С. 1920). Присутствуют и формулировки, относящиеся к добровольно перешедшим на русскую территорию одиночным черкесам, а иногда и черкесам со своими крепостными, например, черкес Кусель «выбежал с крестьянином» (С. 1921), а некий анонимный, «подвластный», как указано в тексте, черкес даже «выбежал с хозяином» (С. 1921). Татарин Сойн (Емельянов Симион) в 1796 году «выбежал из плена. Желает принять христианскую веру и стать черноморским казаком» (Там же). А схваченные натухайцами армяне, в частности некоторые священнослужители, выкупались из плена своими единоверцами закубанскими армянами (С. 1923). В отдельных случаях, наоборот, имевшие в своём владении русских пленных солдат горские армяне освобождали их за выкуп, то есть фактически продавали (С. 1925).Черкесы также охотно покупали пленников, захваченных татарами, натухайцами, ногайцами (С. 1930).Некоторых пленников, например отдельных русских солдат, обменивали на черкесских пленных, «представляли на обмен» или «обменен на имущество хищников» (С. 1933, 1937-1952). Процесс обмена пленными, а также выход из Закубанья на русскую сторону черкесов, зачастую с семьями, а также армян, греков, ногайцев, как видно из данной таблицы, заметно активизировался в начале XIX века, примерно с 1803 года, и впоследствии интенсивно продолжался (С. 1956-1978). А с 1808 года, как явствует из представленных в данном приложении сведений, отмечается заметное увеличение выкупа русских пленников из черкесского плена (С. 1979-1981). С этого же года заметно активизируется переход, иногда даже коллективный, на русскую сторону ногайцев из Закубанья. Как отмечалось в документах, «вышел/вышла вместе с соплеменниками» или «вышел/вышла в поисках защиты от грабительства черкесов» (C. 1980-1984).

В 1810 году на русскую территорию, спасаясь от преследований и насилий со стороны черкесов, вместе со своими семьями перешли являвшиеся турецкоподданными греки и армяне. В документах отмечалось: «Грек. Турецкоподданный. Перешел на жительство в Россию с семейством. Всего 8 человек» (С. 1986), «Армянин. Турецкоподданный. Желает вступить в русское подданство», «Армянка. Турецкоподданная. Желает вступить в русское подданство» (С. 1988). Зафиксирован и довольно примечательный случай, когда захваченные черкесами и проданные в турецкое рабство русские военнослужащие, гражданские лица, включая детей, абазинцы, в основном женщины, и некоторые мужчинычеркесы в 1810 году были освобождены моряками русского корвета «Крым», перехватившими шедшее в Турцию судно с невольниками (С. 1989-1995). Из черкесского плена бежали на русскую территорию и турки, включая женщин и детей (С. 1995). Официальные документы бесстрастно фиксировали все случаи бегства, обмена, выкупа 
черкесских пленников. Отмечались и очень редкие, единичные, но в то же время весьма и весьма своеобразные случаи. Например, 12 марта 1815 года было отмечено, что черкешенка Фатьма выкуплена у черкесов владельцем питейной конторы (С. 2015). А запись от 28 марта этого же года гласила, что Найдёнова Дарья «Малороссиянка. Захвачена 15 августа 1814 г. на Малой Понурке. Выкрана черкесами у других черкесов и представлена русским на продажу. Выкуплена» (С. 2015). 6 августа из черкесского плена бежали и вышли на русский кордон два поляка, воевавшие во французской армии, Зигмундовский Ян и Велександрович Симон, в отношении каждого из них было отмечено: «Поляк. Солдат французской армии. Взят в плен под Можайском в 1812 г. Отправлен на Кавказскую линию в Ставрополь. Находился под надзором. Захвачен черкесами в 1813 г. Бежал» (С. 2019).

В июле 1823 года на русскую территорию сбежал черкесский мальчик Магмет, который «оставшись в малолетстве без отца и матери, продан своими людьми в рабство. Пожелал освободиться защитою российского начальства. Потому и бежал» (С. 2041). В 1834 году в одном из официальных докладов было сказано, что на русскую сторону перебежал черкес Пшебисим, который «жил у владетеля Магмет Аббата. Отец Габатар и мать Перув. По прошествии 20 лет князь Магмет разорил их, отца куда-то продал, а его взял к себе. Связал жену Салих, бил ее, держал связанной сутки и хотел лишить жизни. Бежал вместе с семьей» (С. 2070). Как видим, за судьбой каждого бывшего черкесского пленника-раба, без различия их национальностей, вероисповедания и сословного статуса стояла своя жизненная трагедия. При этом, правда, удачный побег, обмен или выкуп позволяли некоторым из них спасти свою жизнь. Но многие тысячи жизней были в прямом смысле слова загублены в бесчеловечном черкесском рабстве.

Необходимо особо отметить, что выявление, анализ и систематизация документов и их сведение в единую таблицу, представленную в особом приложении, явилось своеобразной квинтэссенцией рассматриваемого документального сборника, лаконичным, но очень ёмким, всесторонним и содержательным выражением заложенной и успешно реализованной в данном сборнике общей авторской исследовательской концепции.

В качестве замечаний и рекомендаций относительно введения и содержания рассматриваемого сборника документов можно отметить следующее.

Автор-составитель озаглавил данный документальный сборник как «Черкесские невольничьи повествования», в то же время необходимо отметить, что, во-первых, данное название сборника представляется несколько условным, во-вторых, содержащийся в нём основной массив документов относится не столько к собственно невольничьим повествованиям как таковым, сколько к официальному делопроизводству русских военных и гражданских ведомств, органов Черноморского, с 1861 г. Кубанского казачьего войска. Представляется, что более оптимальным являлось бы название сборника документов как «Рабство в Черкессии в документах», или «Источники по вопросу рабства в Черкессии», или, в случае следования авторскому подходу, «Черкесские невольничьи хроники».

Приведённый в книге список используемых в сборнике сокращений слов и выражений (C. 1434) необходимо было поставить не в самом начале сборника, а наоборот, в его конце.

Представленный сборник документов «Черкесские невольничьи повествования», содержащий очень значительный и разноплановый архивный документальный материал по таким сложным и неоднозначным вопросам, как сущность, масштабы и роль рабства в черкесском обществе; жизнь и быт рабов многих национальностей, отражение их в свидетельствах непосредственно самих бывших невольников; взаимоотношения русской военной и гражданской администрации с горцами в свете данного явления, без сомнения, станет важной источниковой базой дальнейших научных исследований по истории черкесов-адыгов, Северо-Западного и Центрального Кавказа, Кавказской войны, противоречивых и крайне неоднозначных практик русско-черкесских конфликтных и бесконфликтных отношений. Публикуемые в нём документы позволят учёнымкавказоведам с новых ракурсов взглянуть как собственно на историю адыгских народов, их жизнедеятельность, её особенности, включая и такое значимое социально-экономическое явление, как рабовладение, его однозначно негативное влияние на развитие и последующий серьёзный внутренний кризис самого черкесского общества, жизни и судьбы черкесских рабов и крепостных, так и на очень сложные взаимоотношения с горцами русской администрации в крае, черноморских, впоследствии кубанских и терских казаков, в целом 
на судьбы всех проживавших в крае народов. Сборник документов «Черкесские невольничьи повествования» безусловно, вызовет значительный интерес не только учёных-историков, но и краеведов, всех интересующихся историей политической, социально-экономической, военной историей, региональной историей, в частности историей и этнологией СевероЗападного и Центрального Кавказа.

\section{Литература}

Cherkasov, 2020 - Cherkasov, A.A. The Circassian Slave Narratives (A Documentary Collection) // Bylye Gody. 2020. 57-1(3-1): 1415-2266.

\section{References}

Cherkasov, 2020 - Cherkasov, A.A. (2020). The Circassian Slave Narratives (A Documentary Collection). Bylye Gody. 57-1(3-1): 1415-2266.

\section{Черкесские невольничьи повествования (Сборник документов). Автор-составитель и автор вводной статьи А.А. Черкасов. Былые годы. 2020. Том 57-1. Номер 3-1. Специальный выпуск. Страницы 1415-2266.}

\section{Владимир Петрович Трут а , *}

а Донской государственный технический университет, Ростов-на-Дону, Российская Федерация

Аннотация. В представленной рецензии анализируется сборник документов «Черкесские невольничьи повествования». Особое внимание уделено рассмотрению предваряющей его основное содержание научной статьи автора-составителя сборника А.А. Черкасова. Всесторонне охарактеризовано содержание данного сборника документов, проанализированы представленные в нём важные, интересные, разноплановые источниковые материалы, подавляющее большинство которых впервые вводится в научный оборот. Охарактеризованы происхождение и основное содержание документов, вошедших в сборник, рассмотрены наиболее важные и интересные из них. Определены научная актуальность и значение представленных в сборнике документов для дальнейших научных исследований по проблематике русско-черкесских взаимоотношений в период Кавказской войны, социально-экономического развития черкесского общества.

Ключевые слова: «Черкесские невольничьи повествования», сборник документов, Черкессия.

\footnotetext{
${ }^{*}$ Корреспондирующий автор

Адреса электронной почты: trut.vladimir@rambler.ru (В.П. Трут)
} 